\title{
Anti-arthritic Activity of the Aqueous Extract of the Aerial Parts of Mitracarpus scaber (Rubiaceae) Zucc in Rats Wistar
}

\author{
Georges Abizi*, Ouattara-Soro Fatou Scherazade, Ernest Zougrou N'guessan, \\ John Kouadio Kouakou, Emile Begbin Kouassi, Sévérin Koffi, Jean-Jacques Kablan Kassi, \\ Alassane Koné
}

Laboratory of Biology and Health, University Felix Houphouet-Boigny (UFHB), Abidjan, Cote d'Ivoire

\section{Email address:}

georgesabizi@gmail.com (G. Abizi)

${ }^{*}$ Corresponding author

\section{To cite this article:}

Georges Abizi, Ouattara-Soro Fatou Scherazade, Ernest Zougrou N'guessan, John Kouadio Kouakou, Emile Begbin Kouassi, Sévérin Koffi, Jean-Jacques Kablan Kassi, Alassane Koné. Anti-arthritic Activity of the Aqueous Extract of the Aerial Parts of Mitracarpus scaber (Rubiaceae) Zucc in Rats Wistar. Journal of Diseases and Medicinal Plants. Vol. 7, No. 1, 2021, pp. 22-29.

doi: 10.11648/j.jdmp.20210701.14

Received: February 22, 2021; Accepted: March 8, 2021; Published: March 26, 2021

\begin{abstract}
Arthritis is an autoimmune disease characterized by joint inflammation, the treatment of this disease requires the use of non-steroidal or steroidal anti-inflammatory drugs. Given the many side effects associated with conventional antiinflammatory drugs, the use of herbal medicines would benefit patients. Mitracarpus scaber (Rubiaceae), is a herb whose leaves are used to treat skin conditions and relieve pain in the limbs. To elucidate the traditional use of the aerial parts of $M$. scaber, the present study was conducted on arthritic rats induced by Freund's complete adjuvant. Arthritis was induced in Wistar rats by injecting Freund's complete adjuvant solution into the right hind leg. Diclofenac and Celebrex were chosen as reference molecules. Administration of Diclofenac (5 mg/kg body weight) and Celebrex (10 mg/kg body weight) and the aqueous extract of the aerial parts of $M$. scaber at doses of 200; 400 and $800 \mathrm{mg} / \mathrm{kg}$ body weight began the day after injection and continued for 20 days. Leg swelling, biochemical and hematological parameters as well as fibrinogen levels were evaluated. Oral administration of the extract significantly suppressed inflammatory responses in the joints of arthritic rats. It did not cause liver damage in the rats during the twenty (20) days of treatment. These results indicate that the aqueous extract of the aerial parts of M. scaber prevents the pathological development of arthritis in rats. The active ingredients present in the extract could be potential agents for the treatment of inflammation and arthritis.
\end{abstract}

Keywords: Mitracarpus scaber, Arthritis, Anti-inflammatory

\section{Introduction}

Arthritis is an autoimmune disease characterized by chronic inflammation of one or more joints resulting in the destruction of cartilage. It is often associated with aging, but can also affect children. It combines degradation, repair, and inflammation of the articular cartilage, bone and surrounding tissues, resulting in pain, cracking, and deformity, which patients complain about [1]. The disease affects almost $1 \%$ of the world's population, in sub-Saharan Africa the overall prevalence is estimated at $0.3 \%$ with a clear difference between rural areas, of which it is estimated at $0.9 \%$; and
$0.68 \%$ for urban areas [2].

Drugs currently available for the treatment of arthritis include analgesics, steroids, non-steroidal antiinflammatory drugs (NSAIDs) and immunosuppressive agents. These different drugs have potential side effects on the gastrointestinal tract, blood cell counts and the immune system [3]. New drugs are therefore needed that offer effective treatment with fewer side effects and are relatively less expensive. Thus, natural phytochemicals may be a better alternative strategy for the effective treatment of 
arthritis.

Indeed, the leaves of Mitracarpus scaber (Rubiaceae) are used in traditional medicine to treat skin infections such as tartar and ringworm, and also to relieve headaches and limb pain [4]. Studies have shown that the aerial parts of Mitracarpus scaber contain molecules involved in the treatment of skin wounds, inflammation, and leukemia.

The objective of the present study is to prove the therapeutic efficacy of the aqueous extract of the aerial parts of $M$. scaber in arthritic rats induced by Freund's complete adjuvant.

\section{Materials and Methods}

\subsection{Materials}

\subsubsection{Plant Material}

Fresh aerial parts of $M$. scaber were collected in Daloa, central-western Côte d'Ivoire, during September 2020. The plant was identified at the National Floristic Center of the Félix Houphouët-Boigny University. The plants were dried in the shade at room temperature for 15 days and reduced to powder using an electric grinder (Retsch, model GM 300). The powder was used for the preparation of the extract.

\subsubsection{Animal Material}

Ten (10) week old male and female Wistar strain rats weighing approximately $150-180 \mathrm{~g}$ were used for the study. They were housed in polypropylene cages and fed ad libitum with a standard diet and water. The animals were exposed to a 12-hour alternating cycle of darkness and light.

\subsection{Methods}

\subsubsection{Preparation of the Crude Extract}

The powder obtained was used for the preparation of the total aqueous extract of the aerial parts of Mitracarpus scaber following the method of Yapo, Konkon, Coulibaly, Camara and Zirihi [5]. Fifty grams (50 g) of powder was diluted in one (1) liter of distilled water in the blender and mixed for 10 minutes. The resulting homogenate was filtered twice on white cloth square and then five times on absorbent cotton. The resulting filtrate was evaporated at $50^{\circ} \mathrm{C}$ in an oven.

\subsubsection{Phytochemical Screening}

Phytochemical screening was performed on the aqueous extract according to the methods used by N'guessan, Kadja, Zirihi, Traoré and Aké -Assi [6]. It required various reagents. The search for catechic tannins was possible thanks to Stiasny's reagent and sodium acetate. For the characterization of gallic tannins, Stiasny's reagent, sodium acetate and ferric chloride were used. Acetic anhydride and concentrated sulfuric acid were required for the detection of sterols and polyterpenes. Hydrochloric alcohol diluted two (02) times, magnesium chips and isoamyl alcohol were used to search for flavonoids. The alcoholic solution of $2 \%$ ferric chloride allowed the characterization of polyphenols. The Bornstraëgen reagent, chloroform, ammonia diluted twice and hydrochloric acid were used to search for quinonic substances. Alkaloids were characterized using alcohol at $60^{\circ}$, Burchard's reagent (iodo-iodide reagent) and Dragendorff's reagent (potassium iodobismuthate reagent). The presence of foams after stirring of the aqueous solution of the extract allowed to highlight the saponosides.

\subsubsection{Freund's Complete Adjuvant (FCA) Induced Arthritic Model}

Arthritis was induced according to the method of Pan, Xia, Guo and Kong [7]. It was induced in rats aged six to eight weeks by the injection of $40 \mu 1$ of Freund's complete adjuvant solution under the plantar fascia of the right hind leg of the rats. The diameter of the injected leg was measured by digital caliper at day zero (before injection) and at days $1 ; 4$; $8 ; 12 ; 16$ and 20 (after injection) of Freund's complete adjuvant solution. Treatment began the day after injection of Freund's adjuvant and continued for twenty days. Six groups of six rats each (three males and three females) received the following oral treatments once daily:

1) A control group receiving distilled water

2) Two groups treated with diclofenac and celebrex at 5 and $10 \mathrm{mg} / \mathrm{kg}$ body weight respectively.

3) Three groups treated with the aqueous extract of the aerial parts of M. scaber at 200, 400 and $800 \mathrm{mg} / \mathrm{kg}$ body weight.

Rat weights were recorded before induction of inflammation, and after induction at four-day intervals for fourteen days. At the end of the experimental period the animals were anaesthetized with ether after 18 hours of fasting. Blood was collected in dry tubes, EDTA-containing tubes and citrated tubes for the respective determinations of biochemical parameters (ALAT, ASAT and albumin), proinflammatory cells and fibrinogen.

The importance of arthritis is assessed by determining the percentage increase in leg diameter (\% AUG) of the animal.

$$
\% A U G=\left[\left(D_{t n}-D_{t 0}\right) / D_{t 0}\right] * 100
$$

$D_{\text {tn: }}$ Diameter of the leg at time $\left(t_{n}\right)$

$\mathrm{D}_{\mathrm{t} 0}$ : Diameter of the leg at time $\left(\mathrm{t}_{0}\right)$

The anti-inflammatory activity was evaluated by calculating the percentage inhibition of edema (\% INH).

$$
\% \mathrm{INH}=\left[\left(\% \mathrm{AUG}_{\text {control }} \% \mathrm{AUG}_{\text {treated }}\right) / \% \mathrm{AUG}_{\text {control }}\right] * 100
$$

\section{Statistical Analysis}

All results were expressed as mean \pm the error on the mean (ESM). Statistical analysis and graphs were performed using Graphpad prism version 8 software. Comparison between three or more groups was evaluated using a one-way analysis of variance (ANOVA) followed by Tukey's multiple comparison test. The level of significance was set at $\mathrm{P}<0.05$. 


\section{Results and Discussion}

\subsection{Results}

\subsubsection{Phytochemical Screening of the Aqueous Extract of the Aerial Parts of Mitracarpus Scaber}

Table 1 shows the results of the phytochemical screening carried out on the aerial parts of M. scaber.

\subsubsection{Effect of Different Treatments on the Evolution of Body Weight in Arthritic Rats}

Immunization of rats with Freund's complete adjuvant caused a decrease in weight gain in animals of all lots during the first six (6) days after injection. From day eight (8) onwards the body mass of treated animals increased, this increase was not statistically significant compared to the control (Figure 1).

Table 1. Phytochemical screening of the aqueous extract of the aerial parts of Mitracarpus scaber.

\begin{tabular}{|c|c|c|c|c|c|c|c|c|c|}
\hline & \multirow{2}{*}{$\begin{array}{l}\text { Sterols } \\
\text { Polyterpenes }\end{array}$} & \multirow{2}{*}{ Polyphenols } & \multirow{2}{*}{ Flavonoids } & \multicolumn{2}{|c|}{ Tannins } & \multirow{2}{*}{$\begin{array}{l}\text { Quinonic } \\
\text { substances }\end{array}$} & \multicolumn{2}{|c|}{ Alkaloids } & \multirow{2}{*}{ Saponosides } \\
\hline & & & & Gal & Cat & & D & B & \\
\hline $\begin{array}{l}\text { Composition of the aqueous extract of } \\
\text { the leaves of } M \text {. scaber }\end{array}$ & + & + & + & - & + & + & + & + & + \\
\hline
\end{tabular}

+ : Presence

- Absence

G: Gallic; Cat: Catechism; D: DRANGENDORFF; B: BOUCHARDAT

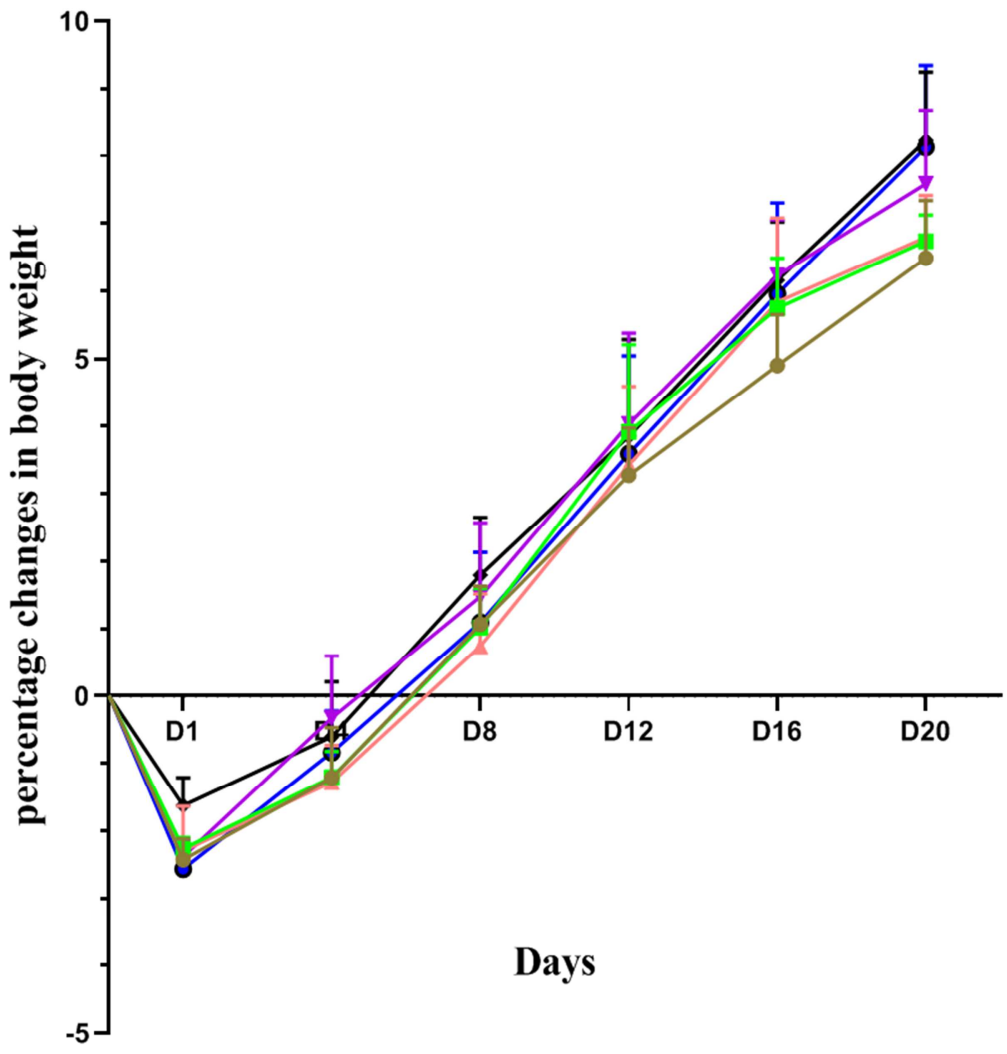



$\neg 800 \mathrm{mg} / \mathrm{kg} \mathrm{bw}$

Figure 1. Effect of different treatment on rat body weight in CFA-induced arthritis.

\subsubsection{Effect of Different Treatments on Freund's Fully Adjuvanted Arthritis}

\section{(i) Freund's Adjuvant-Induced Increase in Leg Oedema}

The injection of Freund's adjuvant caused an increase in the legs of the rats, this increase was palpable the day after the injection. Oral administration of the aqueous extract of the aerial parts of $M$. scaber and the reference molecules significantly reduced foot edema in rats compared to controls (Figure 2). At days sixteen and twenty of treatment, the extract at the various doses and the reference molecules significantly $(p<0,0001)$ prevented the increase in foot edema in rats compared to controls.

\section{(ii) Inhibition of Inflammation Induced by Freund's Adjuvant Injection}

Evaluation of the percentage inhibition shows that the aqueous extract of $M$. scaber parts has antiarthritic properties. On the eighth day of treatment, the extract at a dose of 200 and $400 \mathrm{mg} / \mathrm{kg}$ body weight showed mean percentages of inhibition of $53.77 \pm 2.42 \%$ and $48.55 \pm 4.26 \%$, respectively, similar to that of Diclofenac at a dose of $5 \mathrm{mg} / \mathrm{kg}$ body weight $(50.61 \pm 3.90)$. The same activity was observed on the twelfth and sixteenth days. On the twelfth day of treatment the inhibitory activity of the extract at the dose of $800 \mathrm{mg} / \mathrm{kg}$ body weight was low. This low activity was not statistically 
significant compared to that of Diclofenac. From the sixteenth day the percentages of inhibition of the extract at the different doses were higher compared to Diclofenac. This increase was not statistically significant (Figure 3a).

Compared to Celebrex, the extract at 200 and $400 \mathrm{mg} / \mathrm{kg}$ body weight showed approximate percentages of inhibition to Celebrex. The $800 \mathrm{mg} / \mathrm{kg}$ body weight dose of the extract showed low percentages of inhibition during treatment, with the lowest percentage of inhibition $(41.30 \pm 2.34)$ observed on day 12 compared to Celebrex (60.69 \pm 1.60$)$ (Figure 3b).

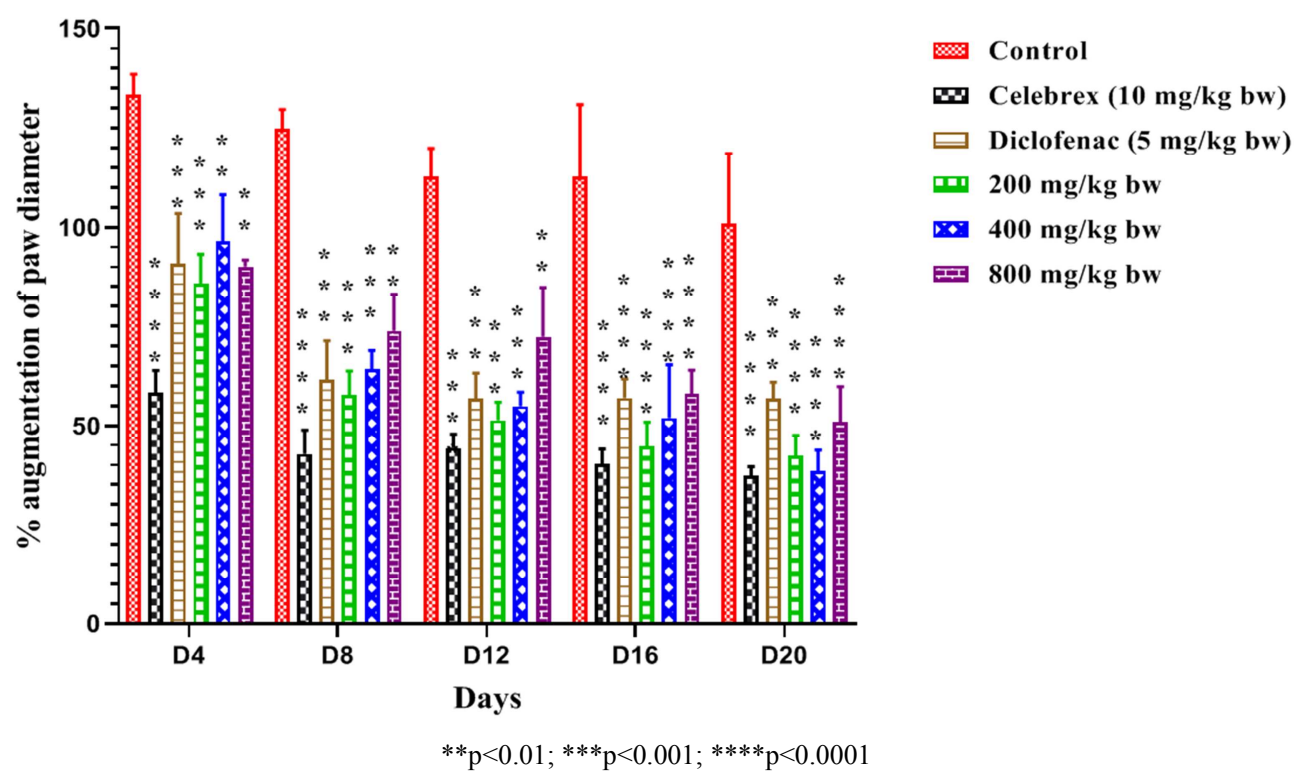

Figure 2. Effect of different treatments on the percentage increase in leg edema induced by Freund's adjuvant injection.
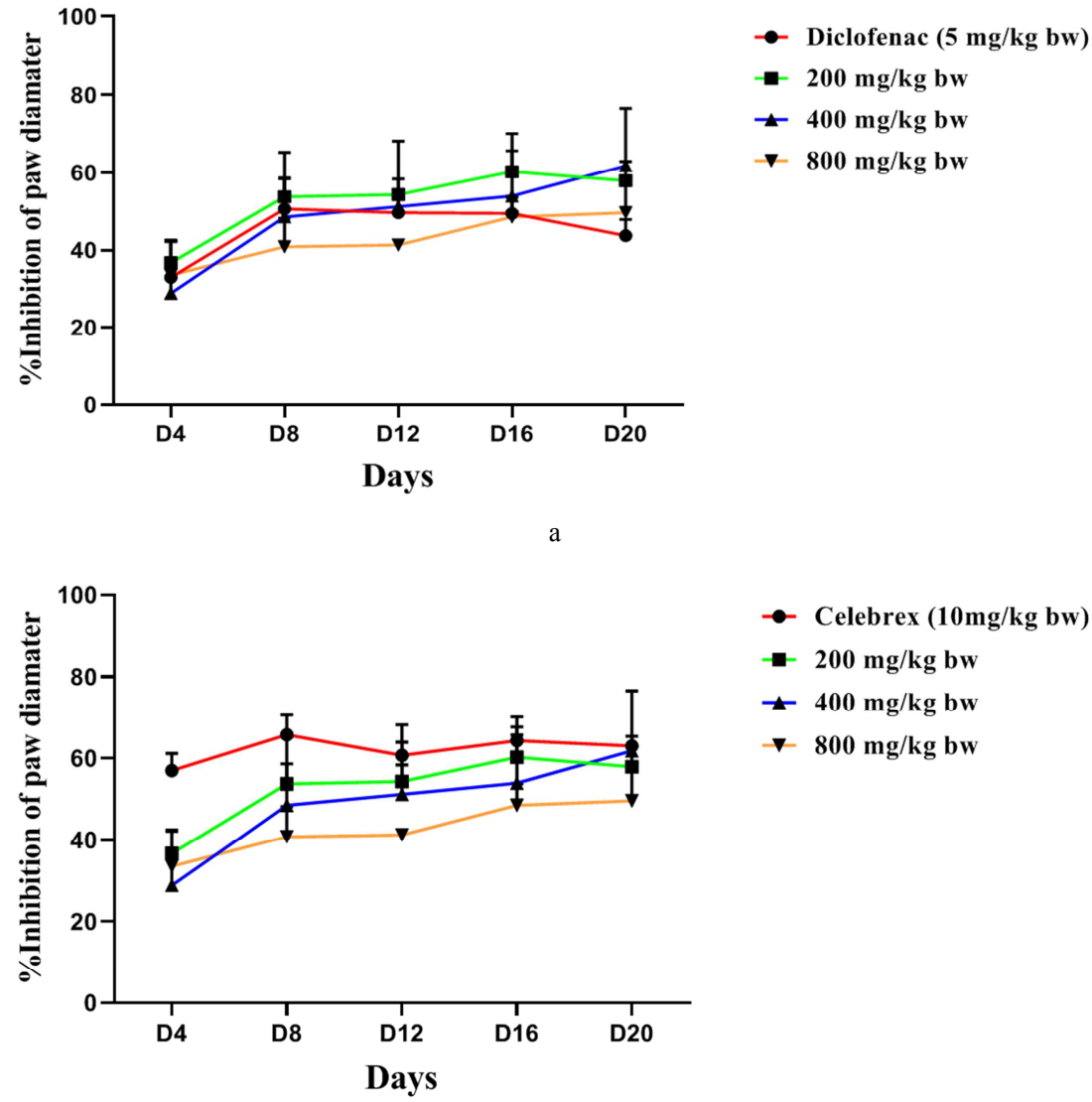

- Celebrex $(10 \mathrm{mg} / \mathrm{kg}$ bw)

- $200 \mathrm{mg} / \mathrm{kg} \mathrm{bw}$

$\leftarrow 400 \mathrm{mg} / \mathrm{kg} \mathrm{bw}$

$\checkmark 800 \mathrm{mg} / \mathrm{kg} \mathrm{bw}$

b

Figure 3. Effect of different treatments on the percentage of inhibition of inflammation induced by Freund's adjuvant. 


\subsubsection{Effect of Different Treatments on Biochemical Parameters and Fibrinogen in Arthritic Rats}

Figures $4 \mathrm{a}$ and $4 \mathrm{~b}$ show a non-significant $(\mathrm{p}>0,05)$ decrease in transaminase levels compared to controls. With respect to albumin, the different treatments resulted in a significant increase in serum albumin levels, this increase was $43.025 ; 38.975 ; 42.875 ; 42.700$ and $41.425 \mathrm{IU} / \mathrm{L}$ respectively in the lots treated with Celebrex, Diclofenac and the extract at the different doses $(200,400$ and $800 \mathrm{mg} / \mathrm{kg}$ body weight) compared to the control lot whose serum albumin level was 29.967 IU/L (Figure 4c).

Fibrinogen is considered one of the proteins in the acute phase of inflammation. In Celebrex-treated rats, fibrinogen levels decreased in a non-significant manner $(p<0,05)$. In batches treated with the extract at 200 and $400 \mathrm{mg} / \mathrm{kg}$ body weight, there was a significant $(p<0,01)$ decrease in fibrinogen levels $(p<0,01)$. Non-significant decreases were noted in rats treated with Diclofenac and in rats treated with the extract at $800 \mathrm{mg} / \mathrm{kg}$ body weight (Figure $4 \mathrm{~d}$ ).

Table 2. Effect of different treatments on hematological parameters of arthritic rats.

\begin{tabular}{|c|c|c|c|c|c|c|c|}
\hline \multirow{2}{*}{ Parameters } & \multirow{2}{*}{ Units } & \multicolumn{6}{|l|}{ Doses } \\
\hline & & Control & Diclofénac ( $5 \mathrm{mg} / \mathrm{kg}$ bw) & Celebrex (10 mg/kg bw) & $200 \mathrm{mg} / \mathrm{kg} \mathrm{bw}$ & $400 \mathrm{mg} / \mathrm{kg} \mathrm{bw}$ & $800 \mathrm{mg} / \mathrm{kg} \mathrm{bw}$ \\
\hline White blood cells & $103 / \mu 1$ & $12,01 \pm 0,31$ & $11,70 \pm 0,36$ & $10,51 \pm 0,59$ & $10,79 \pm 0,60$ & $10,35 \pm 0,57$ & $9,23 \pm 0,52$ \\
\hline Red blood cells & $106 / \mu 1$ & $8,04 \pm 0,4$ & $7,66 \pm 0,4$ & $8,01 \pm 0,1$ & $7,13 \pm 0,5$ & $7,34 \pm 0,3$ & $7,95 \pm 0,12$ \\
\hline Hemoglobin & $\mathrm{g} / \mathrm{dl}$ & $13,38 \pm 0,7$ & $12,63 \pm 05$ & $13,23 \pm 0,12$ & $12,03 \pm 0,8$ & $12,03 \pm 0,5$ & $13,08 \pm 0,4$ \\
\hline Lymphocytes & $103 / \mu 1$ & $7,68 \pm 0,12$ & $6,95 \pm 0,32$ & $7,240 \pm 0,25$ & $7,45 \pm 0,35$ & $6,54 \pm 0,22$ & $6,05 \pm 0,38$ \\
\hline Eosinophiles & $103 / \mu 1$ & $0,36 \pm 0,03$ & $0,27 \pm 0,02$ & $0,30 \pm 0,00$ & $0,19 \pm 0,03 * * *$ & $0,16 \pm 0,02 * * *$ & $0,13 \pm 0,01 * * *$ \\
\hline Basophiles & $103 / \mu 1$ & $0,053 \pm 0,00$ & $0,048 \pm 0,00$ & $0,043 \pm 0,00$ & $0,023 \pm 0,00 * *$ & $0,023 \pm 0,00 * *$ & $0,015 \pm 0,00 * * *$ \\
\hline Neutrophils & $103 / \mu 1$ & $4,49 \pm 0,19$ & $4,29 \pm 0,25$ & $3,53 \pm 0,20$ & $2,87 \pm 0,31 * *$ & $3,25 \pm 0,41 *$ & $2,59 \pm 0,03 * *$ \\
\hline Monocytes & $103 / \mu 1$ & $0,59 \pm 0,02$ & $0,57 \pm 0,02$ & $0,41 \pm 0,05^{* *}$ & $0,26 \pm 0,02 * * *$ & $0,37 \pm 0,03 * *$ & $0,45 \pm 0,02 *$ \\
\hline
\end{tabular}

${ }^{*} \mathrm{p}<0,05 ;{ }^{* *} \mathrm{p}<0,01 ; * * \mathrm{p}<0,001 ;$ values without $(*) \mathrm{p}<0,5$

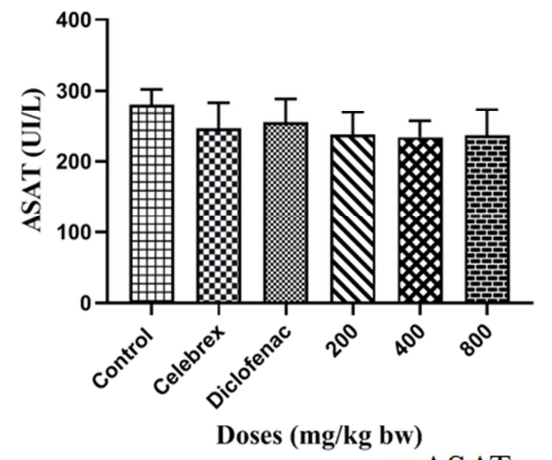

a: ASAT

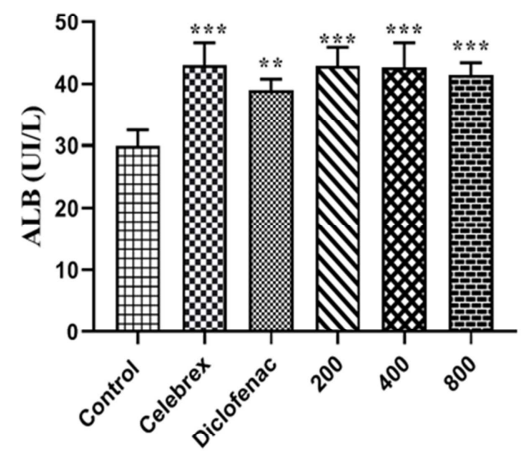

Doses (mg/kg bw)

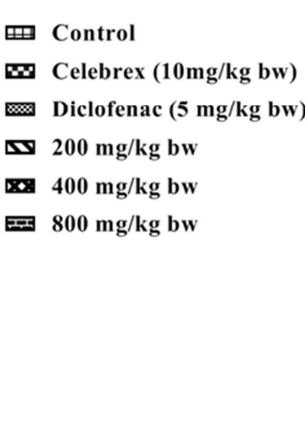

䧃 Control

W0 Celebrex (10 mg/kg bw) Diclofenac $(5 \mathrm{mg} / \mathrm{kg}$ bw)

$200 \mathrm{mg} / \mathrm{kg}$ bw

$400 \mathrm{mg} / \mathrm{kg}$ bw

四 $800 \mathrm{mg} / \mathrm{kg}$ bw

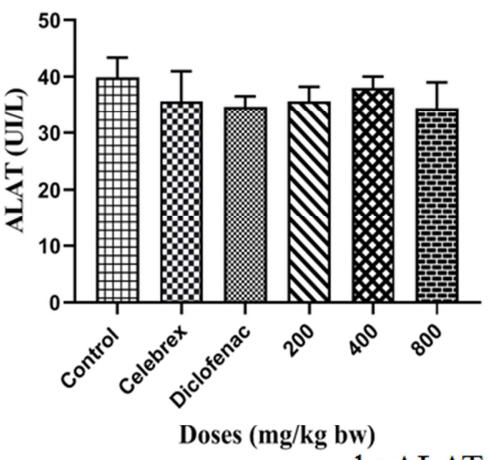

b: ALAT



Doses (mg/kg bw )

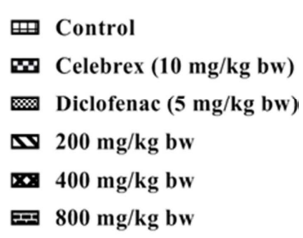

d: Fibrinogen

${ }^{*} \mathrm{p}<0,05 ; * * \mathrm{p}<0,01 ; * * \mathrm{p}<0,001 ;$ values without $(*) \mathrm{p}<0,5$

Figure 4. Effect of different treatments on biochemical parameters and fibrinogen in arthritic rats.

\subsubsection{Effect of Different Treatments on Hematological Parameters of Arthritic Rats}

The effect of the different treatments on hematological parameters in adjuvant-induced arthritic rats is presented in table 2. Non-significant decreases in hemoglobin, red blood cell and white blood cell counts were observed in treated versus control lots. The same findings were seen in lymphocyte, eosinophil, basophil, neutrophil, and monocyte counts, but with significant differences in the batches treated with Celebrex and those treated with the aqueous extract of 
the aerial portions of $M$. scaber at the different doses.

\subsection{Discussion}

The aqueous extract of the aerial parts of $M$. scaber revealed the presence of important chemical groups such as: sterols, polyterpenes, flavonoids, quinonic substances, catechic tannins, alkaloids and saponosides. The richness of the leaves of this plant in chemical compounds could explain its use in traditional medicine for the treatment of skin diseases, pain in the limbs, fever. These results are similar to those of Adebayo, Adedokun, Ayinde and Ume [8], these authors have highlighted the presence in the methanolic extract of $M$. scaber leaves in addition to the above-mentioned chemical compounds of other compounds such as: glycosides.

Indeed, sterols and polyterpenes are used for their antipyretic and analgesic properties. Flavonoids are endowed with antioxidant, anti-inflammatory and analgesic properties [9-12]. Some flavonoid compounds have also been shown to possess sedative, anticonvulsant, and immunomodulatory properties [13, 14]. Catechic tannins have a strong antioxidant activity, they inhibit the formation of superoxide radicals [15]. Numerous studies indicate that tannins have anti-inflammatory and antimicrobial activities and have a protective function against UV rays and oxidative stress [16]. Saponosides are used therapeutically for their antiinflammatory, antioxidant and anti-cancer effects [17]. Quinonic substances have anti-tumor properties. Quinones from the group of anthraquinones, naphthoquinones and benzoquinones have been studied for their growth-inhibiting effect on cultured malignant cells, such as cancer cells of the ovary, breast, prostate, melanoma, lung, colon and pancreas [18]. Alkaloids have antileukemic; antipyretic and antiparasitic properties $[19,20]$.

Freund's fully adjuvant-induced arthritic method is used in this study to evaluate the antiarthritic activity of the aqueous extract of the aerial parts of M. scaber. The decrease in weight gain in rats after day one through day four of Freund's Full-Adjuvant injection may be due to its immunogenic effect. Indeed, weight loss is associated with reduced food consumption, metabolic changes and skeletal muscle proteolysis [21]. Similar results were obtained by Yoshikawa, Tanaka and Kondo [22] in arthritic studies in rats. Determination of leg edema in rats is a sensitive and rapid method for assessing the degree of inflammation and the therapeutic effects of drugs. In Freund's fully adjuvantinduced arthritic model, rats developed chronic edema in their joint. As a result, this change leads to the destruction of joint function in the affected rats. The adjuvant induced an increase in edema in the control batch, with the maximum increase being reached on day four after injection. According to Saleem, Saleem, Akhtar, Shahzad and Jahan [23], adjuvant-induced arthritis occurs in two stages. The acute stage lasts from one to ten days and is associated with primary lesions; while the chronic stage lasts from 11 to 28 days and is associated with synovitis. However, treatment with the extract at doses of 200, 400 and $800 \mathrm{mg} / \mathrm{kg}$ body weight, Diclofenac and Celebrex significantly reduced edema during the twenty days of treatment. The extract at doses of 200 and $400 \mathrm{mg} / \mathrm{kg}$ body weight provided better edema inhibitory activity compared to Diclofenac. However, this was not the case compared to Celebrex. The inhibitory effect of the extract at the various doses was not significantly lower than that of Celebrex. The reference molecules used in this work are non-steroidal anti-inflammatory drugs, but with different mechanisms of action. Diclofenac is a non-selective inhibitor of cyclooxygenases type 1 and 2 . In contrast, Celebrex selectively inhibits type 2 cyclooxygenase. In this study, the extract in the acute phase of inflammation acts like Diclofenac; in long-term treatment, the extract at doses of 200 and $400 \mathrm{mg} / \mathrm{kg}$ body weight has approximately the same effects as Celebrex. The extract would specifically block the activation of type 2 cyclooxygenase. This cyclooxygenase 2 inhibitory activity is believed to be due to the presence of flavonoids in the aqueous extract of the aerial parts of $M$. scaber. According to work carried out in vitro by Kim, Son, Chang and Kang [24], flavonoids inhibit the induction and/or activity of cyclooxygenase 2 by suppressing the transcription of cyclooxygenase 2 by enzymes such as tyrosine kinase and protein kinase $\mathrm{C}$.

In addition, significant increases in serum albumin levels were observed. Arthritis induced by Freund's complete adjuvant causes changes in plasma protein concentrations that are manifested by a decrease in albumin levels [25]. During inflammation, released mediators such as histamine, bradykinin and prostaglandins increase the permeability of vascular tissues to albumin, leading to a reduction in serum albumin levels [26]. Treatment with the aqueous extract of $M$. scaber's aerial parts and non-steroidal anti-inflammatory drugs significantly increased serum albumin levels. Thus, the extract would have suppressive effects on the mediators of inflammation.

In this study, the decrease in fibrinogen levels in treated rats would justify the repair of adjuvant-induced tissue damage. Similar results were obtained by Ekambaram, Perumal and Subramanian [27].

During the twenty days of treatment, no significant changes in red blood cell counts and hemoglobin levels were observed in the treated lots compared to the control. Red blood cell and hemoglobin counts in treated and untreated arthritic rats remained within the normal range (6-10.106/ $\mu 1$ and 11-20 g/dl, respectively) [28]. In this study arthritis did not cause anemia in the animals. However, the results of Ekambaram, Perumal and Subramanian [27] showed that arthritis caused anemia in untreated arthritic rats. This anemic condition is thought to be due to abnormal iron storage in synovial tissue and the inability of the bone marrow to respond to anemia. Inflammation leads to an increased accumulation of monocytes and granulocytes. This accumulation persists during chronic inflammation. Doses of 200,400 and $800 \mathrm{mg} / \mathrm{kg}$ body weight significantly reduced the blood levels of granulocytes and monocytes in rats treated with the aqueous extract of the aerial parts of $M$. scaber compared to untreated arthritic rats. Indeed, the aqueous extract of $M$. scaber aerial parts would have 
immunoregulatory effects, preventing the proliferation of proinflammatory cells.

\section{Conclusion}

The results of the present study lead to the conclusion that the aqueous extract of the aerial parts of M. scaber has significantly antiarthritic properties in rats. This good activity of the plant would be due to the presence of polyphenols and flavonoids in the aqueous extract of the aerial parts. It is therefore important to study the extract on other parameters involved in arthritis. In addition, the extract must be fractionated in order to separate the active phytochemical substances.

\section{Acknowledgements}

The authors express their sincere gratitude to the Université Félix Houphouët-Boigny, particularly to the Unité de Formation et de Recherche (UFR) Biosciences and the UFR Sciences pharmaceutiques for technical assistance. Our thanks go to the Ecole Normale Supérieure (ENS), Abidjan (Ivory Coast) for its collaboration.

\section{References}

[1] Rafal S., (2014). My guide to alternative medicine for everyday health. Marabout Reference.

[2] Mijiyawa M., (1995). Epidemiological and semiological aspects of rheumatoid arthritis in the third world. Rev Rhum; 62: $127-32$

[3] Amraoui N., Mayouf N., Charef N., Baghiani A. \& Arrar L., (2019). Antioxidant, anti-inflammatory and anti-arthritic activities of methanol extract of Tamus communis L. roots. Trop J Pharm Res 18 (7): 1499-1506.

[4] Kouakou L. S., Kouakou G. S., Dally L. I. \& Brou J. K., (2010). Evaluation of the analgesic activity of the aqueous extract of the leaves of Mitracarpus scaber Zucc (Rubiaceae), a medicinal plant from Côte d'Ivoire. Int. J. Biol. Chem. Sci. 4 (2): 456-463.

[5] Yapo C. V. Y., Konkon D. G., Coulibaly K., Camara D. \& Zirihi G. N., (2016). Botanical study, evaluation of the antifungal activity on the in vitro growth of Candida albicans and toxicity on HFF cells of leaves of Mallotus oppositifolius (Geiseler) Müller. Arg (Euphorbiaceae). Journal of Animal \& Plant Sciences, 28 (1): 4330-4339.

[6] N'guessan K., Kadja B., Zirihi G. N., Traoré D. \& Aké -Assi L., (2009). Phytochemical screening of some Ivorian medicinal plants used in Krobou country (Agboville, Côte d'Ivoire). Sci. Nat. 6 (1): 1 - 15.

[7] Pan K., Xia X., Guo W. \& Kong L., (2015). Suppressive effects of total alkaloids of Lycopodiastrum casuarinoides on adjuvant-induced arthritis in rats. J Ethnopharmacol; 159: 1722.

[8] Adebayo M. A., Adedokun O., Ayinde B. A. \& Ume O., (2017). Comparative studies on In-vitro radical scavenging potential of methanol extracts of Garcinia kola heck
(Clusiaceae) seeds, Conyza sumatrensis retz (Asteraceae) and Mitracarpus scaber zucc (Rubiaceae) leaves. American Journal of Essential Oils and Natural Products; 5 (2): 33-36.

[9] Wang J. \& Mazza G., (2002). Effects of anthocyanins and other phenolic compounds on the production of tumor necrosis factor $\alpha$ in LPS/IFN- $\gamma$-activated RAW 264.7 marcophages. J. Agric. Food Chem., 50 (4): 850-857.

[10] Pathak D., Pathak K. \& Sigla A. K., (1991). Flavonoids as medicinal agents: recent advances. Fitoterapia, 62: 371-388.

[11] Meyre-Silva C., Yunes R., Santos A. R. S., Magro J. D., Monache F. D., Filho V. C., (1999). Isolation of a CGlycoside Flavonoid with antinociceptive action from Aleurites moluccana Leaves. Planta Medica, 65: 263-294.

[12] Bittar M., Maria de Sousa S., Yunes R., Lento R., Monache F. D. \& Filho V. C., 2000. Antinociceptive activity of 13, 118Binaringenin, a biflavonoid present in plants of the Guttiferae. Planta Medica, 66, 84-86.

[13] Du X. M., Sun N. Y., Takizawa N., Guo Y. T. \& Shoyama Y., (2002). Sedative and anticonvulsant activities of goodyerin, a flavonol glycoside from Goodyera schlechtendaliana. Phytotherapy Research, 3,. 261-263.

[14] Lyu S. Y. \& Park W. B., (2005). Production of cytokine and NO by RAW 264.7 macrophages and PBMC in vitro incubation with flavonoids. Archives of Pharmaceutical Research, 5, 537-581.

[15] Bediaga M., (2011). Ethnobotanical and phytochemical study and biological activities of Nauclea Latifolia (Smith) an African medicinal plant harvested in Mali. PhD thesis. University of Bamako, Mali. p 10.

[16] Scalbert A., Manach C., Morand C., Rémésy C. \& Jiménez L., (2002). Dietary polyphenols and the prevention of diseases. Crit Rev Food Sci Nutr.

[17] Franchomme P., Jollois R. \& Pénoël D., (2001). Aromatherapy exactly. Ed. Roger Jollois.

[18] Kamei H.; Koide T.; Kojima T., Hashimoto Y. \& Hasegawa M., (1998). Cancer Biother. Radiopharm, 13: 185-188.

[19] Dewick, P. M., (2001). Medicinal Natural Products. Wiley, Chapiter 6, 291p.

[20] Jiang, S.; Zeng Q.; Gettayacamin M.; Tungtaeng A.; Wannaying S.; Lim A.; Hansukjariya P.; Okunji C. O.; Zhu S. \& Fang D, (2005). Antimalarial Activities and Therapeutic Properties of Febrifugine Analogs. Antimicrob. Agents Chemother, 49 (3): 1169-1176.

[21] Taksande B. G., Gawande D. Y., Chopde C. T., Umekar M. J. \& Kotagale N. R., (2017). Agmatine ameliorates adjuvant induced arthritis and inflammatory cachexia in rats. Biomed Pharmacother. 86: 271-278.

[22] Yoshikawa T, Tanaka H \& Kondo M., (1985). The increase in lipid peroxidation in rat adjuvant arthritis and its inhibition by Superoxide dismutase. Biochem. Med. 33: 320-326.

[23] Saleem A., Saleem M., Akhtar M. F., Shahzad M. \& Jahan S. (2020). Polystichum braunii extracts inhibit Complete Freund's adjuvant-induced arthritis via upregulation of I- $\kappa \mathrm{B}$, IL-4, and IL-10, downregulation of COX-2, PGE2, IL-1 $\beta$, IL6 , NF- $\kappa \mathrm{B}$, and TNF- $\alpha$, and subsiding oxidative stress. Inflammopharmacology, 28 (6): 1633-1648. 
[24] Kim H. P., Son K. H., Chang H. W. \& Kang S. S. (2004). Anti-inflammatory plant flavonoids and cellular action mechanisms-. Pharmacol Sci. 96 (3): 229-245.

[25] Cawthorne M. A, Palmer E. D. \& Green J., (1976). Adjuvant induced arthritisand drug metabolising enzymes. Biochem. Pharmacol., 25: 2683-2688.

[26] Kohn A. \& Barchet E., (1976). Correlation between albumin permeability and adenosine cyclic monophosphate levels in incubated rat mesentry tissue. CR Seances Soc Biol Ses Fil, 170: $270-330$

[27] Ekambaram S., Perumal S. S. \& Subramanian V., (2010). Evaluation of antiarthritic activity of Strychnos potatorum Linn seeds in Freund's adjuvant induced arthritic rat model. Bio Med Central, 10 (56): 1-10.

[28] Andreu L. E., (2005). Pathological dominants in domestic rats. Bull. Soc. Vét. Prat. de France; 89 (1): 60-76. 